\title{
ANALISIS PREDIKSI KEPAILITAN PADA BANK UMUM SWASTA NASIONAL DEVISA YANG TERDAFTAR DI BURSA EFEK INDONESIA TAHUN 2010 - 2013
}

\author{
Sumaniyatun Fadhilah \\ Indah Kurniawati
}

\begin{abstract}
The purpose of this study is to assess bankruptcy prediction in the National Private Banks Foreign Exchange listed in Indonesian Stock Exchange. This study uses the size of liquidity ratio of working capital to total assets. This study uses the find were the purposive sampling. The population in this study is the National Private Commercial Bank Foreign Exchange listed on the Indonesian Stock Exchange during the period of the study, namely between 2010 until 2013. The sample amounted to 21 banks during the 4 years that have been selected based on specific criteria. Based on the results of the analysis carried out stating that the National Private Commercial Bank Foreign Exchange listed in Indonesian Stock Exchange in 2010 there were $29 \%$ of banks that are insolvent, $71 \%$ of banks that are in the gray area, and no banks that are in not bankruptcy predictions. In 201129 $\%$ of banks that are insolvent, $67 \%$ of banks that are in the gray area and $5 \%$ are located on the banks not bankruptcy prediction. In $201229 \%$ of banks that are insolvent, $67 \%$ of banks that are in the gray area, and $5 \%$ of banks that are in the prediction of the bank is not bankrup. In $201329 \%$ of banks that are in bankruptcy prediction, $71 \%$ of banks that are in the gray area, and there are no banks that are in not bankruptcy predictions. There is no difference in Z-score on bankruptcy prediction National Private Banks Foreign Exchange Listed in Indonesian Stock Exchange between 2010, 2011, 2012, and 2013.
\end{abstract}

Keywords:liquidity, profitability, activity, Altman Z -score modification, bankruptcy prediction.

\section{PENDAHULUAN}

Bank adalah suatu lembaga yang berperan sebagai lembaga perantara keuangan (financial intermediary) antara pihak-pihak yang memiliki kelebihan dana (surplus spending unit) dengan mereka yang membutuhkan dana (deficit spending unit), serta berfungsi untuk memperlancar lalu lintas pembayaran giral (Taswan, 2006: 6). Beberapa bank ditutup akibat mengalami kegagalan. Bank Industri merupakan salah satu bank dalam likuidasi dicabut izin usahanya pada tangggal 1 November 1997 memiliki aset Rp590 miliar sejak tahun 1992 sudah dalam kondisi tidak sehat. Blum (1974) dikutip dalam Munawir (2002: 288) menjelaskan bahwa kegagalan keuangan 
diartikan sebagai ketidakmampuan perusahaan untuk membayar kewajiban keuangannya pada saat jatuh tempo yang menyebabkan perusahaan mengalami kebangkrutan, atau menyebabkan terjadinya perjanjian khusus dengan para kreditor untuk mengurangi atau menghapus utangnya.

Munawir (2002: 292) mengemukakan bahwa laporan keuangan akan dapat dihitung sejumlah rasio keuangan yang lazim dijadikan dasar prediksi kebangkrutan. Beaver (1996) dalam Setyorini (1999) yang menggunakan enam rasio keuangan yaitu cash flow ratios, net income ratios, debt to total assets, liquid assets to total asset ratios, liquid assets to current debts ratios asset. Beaver 1996) Setyorini (1999) menemukan bahwa rasio keuangan terbukti sangat berguna untuk prediksi kebangkrutan dan dapat digunakan untuk membedakan secara akurat perusahaan yang akan jatuh bangkrut dan tidak.

Munculnya berbagai model prediksi kebangkrutan merupakan antisipasi dan sistem peringatan dini terhadap kesulitan keuangan karena model tersebut dapat digunakan sebagai sarana untuk mengidentifikasikan bahkan memperbaiki kondisi sebelum dan sampai pada kondisi krisis atau kebangkrutan. Hal ini yang mendorong perlunya peringatan dini adalah munculnya problematika keuangan yang mengancam operasional perusahaan. Faktor modal dan risiko keuangan mempunyai peranan penting dalam menjelaskan fenomena kepailitan/tekanan keuangan perusahaan tersebut (Endri, 2009).

Hasil penelitian Altman (1968) menunjukkan bahwa penelitiannya dengan menggunakan metoda MDA (Z-Score) dan mampu memprediksi hingga keakuratannya mencapai $95 \%$ pada perusahaan selama 12 bulan. Penelitian Gamayuni (2011) menunjukkan bahwa Model Altman Z-Score terbukti dapat digunakan sebagai alat untuk memprediksi kebangkrutan. Menurut Endri (2009) dalam Bowo (2013) pendekatan MDA dapat mengkombinasikan berbagai rasio menjadi suatu model prediksi yang berarti dan dapat digunakan untuk seluruh perusahaan, baik perusahaan publik, pribadi, manufaktur, ataupun perusahaan jasa dalam berbagai ukuran. Sesuai uraian di atas, maka penulis bermaksud meneliti mengenai analisis prediksi kepailitan pada bank umum swasta nasional devisa yang terdaftar di Bursa Efek Indonesia tahun 2010-2013. 


\section{TINJAUAN PUSTAKA DAN HIPOTESIS}

\section{Bank}

Bank adalah suatu lembaga yang berperan sebagai lembaga perantara keuangan (financial intermediary) antara pihak-pihak yang memiliki kelebihan dana (surplus spending unit) dengan mereka yang membutuhkan dana (deficit spending unit), serta berfungsi untuk memperlancar lalu lintas pembayaran giral (Taswan, 2006: 6). Menurut Undang-Undang Perbankan Nomor 10 Tahun 1998 bank adalah badan usaha yang menghimpun dana dari masyarakat dalam bentuk simpanan dan menyalurkannya ke masyarakat dalam bentuk kredit dan/atau bentuk-bentuk lainnya dalam rangka meningkatkan taraf hidup rakyat banyak.

Bank merupakan lembaga keuangan yang sangat dibutuhkan oleh masyarakat dalam melakukan transaksi keuangan, maupun transaksi lainnya. Bank di Indonesia dibagi menjadi beberapa jenis. Jenis bank dapat dibedakan sesuai dengan fungsi, kepemilikan, status, penetapan harga, dan tingkatannya (Ismail, 2010: 13).

\section{Laporan Keuangan}

Menurut Harahap (1997: 20), laporan keuangan merupakan produk atau hasil akhir dari suatu proses akuntansi. Laporan inilah yang menjadi bahan informasi bagi para pemakainya sebagai salah satu bahan dalam proses pengambilan keputusan. Di samping sebagai informasi laporan keuangan juga sebagai pertanggungjawaban atau accountability. Laporan keuangan juga menggambarkan indikator kesuksesan suatu perusahaan mencapai tujuan. Kasmir (2000) menjelaskan bahwa laporan keuangan bank sebagai berikut:

1) Neraca

Neraca merupakan laporan yang menunjukkan posisi keuangan bank pada tanggal tertentu. Posisi keuangan yang dimaksud adalah posisi aktiva (harta), pasiva (kewajiban dan ekuitas) suatu bank. Penyusunan komponen di dalam neraca didasarkan pada tingkat likuiditas dan jatuh tempo.

2) Laporan Komitmen dan Kontijensi

Laporan komitmen adalah suatu ikatan atau kontrak yang berupa janji yang tidak dapat dibatalkan secara sepihak dan harus dilaksanakan apabila persyaratan yang disepakti bersama dipenuhi. Laporan kontijensi adalah tagihan atau kewajiban 
bank yangmkemungkinan timbulnya tergantung pada terjadi atau tidak terjadinya satu atau lebih peristiwa di masa yang akan datang.

3) Laporan Laba Rugi

Laporan laba rugi adalah laporan keuangan bank yang mengambarkan hasil usaha bank dalam suatu perioda tertentu.

4) Laporan Arus Kas

Laporan arus kas adalah laporan yang menunjukkan semua aspek yang berkaitan dengan kegiatan bank, baik yang berpengaruh langsung maupun tidak langsung terhadap kas.

5) Catatan Atas Laporan Keuangan

Catatan atas laporan keuangan adalah laporan yang berisi catatan tersendiri mengenai posisi devisa neto, menurut jenis mata uang dan aktivitas lainnya.

6) Laporan Keuangan Gabungan dan Konsolidasi

Laporan gabungan adalah laporan dari seluruh cabang-cabang bank yang bersangkutan, baik yang ada di dalam negeri maupun di luar negeri. Laporan konsolidasi adalah laporan bank yang bersangkutan dengan anak perusahaan.

Menurut Kasmir (2000: 255) pihak-pihak yang memiliki kepentingan terhadap laporan keuangan bank adalah pemegang saham, pemerintah, manajemen, karyawan, dan masyarakat luas

\section{Tujuan Laporan Keuangan Bank}

Tujuan umum laporan keuangan menurut SAK (2012), yaitu:

1) Memberikan informasi yang dapat dipercaya mengenai posisi keuangan perusahaan (termasuk bank) pada saat tertentu.

2) Memberikan informasi keuangan yang dapat dipercaya mengenai hasil usaha perusahaan selama perioda akuntansi tertentu.

3) Memberikan informasi yang dapat membantu pihak-pihak yang berkepentingan untuk menilai atau menginterprestasikan kondisi dan potensi suatu perusahaan.

4) Memberikan informasi penting lainnya yang relevan dengan kebutuhan pihakpihak yang berkepentingan dengan laporan kebutuhan yang bersangkutan. 


\section{Rasio Keuangan Bank}

Analisis yang sering digunakan untuk menilai kinerja bank adalah analisis rasio keuangan yang meliputi rasio likuiditas, rasio solvabilitas dan rasio rentabilitas (Munawir, 2002: 337). Rasio tersebut sebagai berikut:

1) Rasio likuiditas adalah kemampuan suatu perusahaan untuk memenuhi kewajiban keuangannya yang harus segera dipenuhi, atau kemampuan perusahaan memenuhi kewajiban keuangan pada saat ditagih.

2) Rasio rentabilitas adalah kemampuan suatu perusahaan untuk menghasilkan laba selama perioae tertentu.

3) Rasio solvabilitas adalah kemampuan perusahaan untuk memenuhi segala kewajiban finansialnya apabila sekiranya perusahaan tersebut pada saat itu dilikuidasikan.

\section{Analisis Z-Score}

Z-score adalah skor yang ditentukan dari hitungan standar kali nisbah-nisbah keuangan yang menunjukkan tingkat kemungkinan kebangkrutan perusahaan. Formula Z-Score untuk memprediksi kebangkrutan dari Altman (1986) merupakan sebuah multivariate formula yang digunakan untuk mengukur kesehatan finansial dari sebuah perusahaan. Altman (1986) menemukan lima jenis rasio keuangan yang dapat dikombinasikan untuk melihat perbedaan antara perusahaan yang bangkrut dan yang tidak bangkrut.

Berkaitan dengan Analisis Z-Score, Altman Modifikasi menyatakan bahwa ada empat rasio yang dapat dikombinasikan untuk memprediksi kepailitan. Rasio-rasio yang digunakan dapat dikategorikan dalam tiga kelompok besar yaitu (Bowo, 2013) rasio likuiditas yag terdiri dari $\mathrm{X}_{1}$, rasio profitabilitas yang terdiri dari $\mathrm{X}_{2}$ dan $\mathrm{X}_{3}$, serta rasio aktivitas yang terdiri dari $\mathrm{X}_{4}$.

\section{Prediksi Kepailitan}

Kebangkrutan adalah suatu kondisi di saat perusahaan mengalami ketidakcukupan dana untuk menjalankan usahanya. Berdasarkan Undang-Undang Republik Indonesia Nomor 37 Tahun 2004 kepailitan adalah sita umum atas semua kekayaan debitor pailit yang pengurusan dan pemberesannya dilakukan oleh kurator 
di bawah pengawasan hakim pengawas sebagaimana diatur dalam undang- undang.

Blum (1974) dikutip dalam Munawir (2002: 288) mengemukakan kegagalan keuangan dapat diartikan sebagai ketidakmampuan perusahaan untuk membayar kewajiban keuangannya pada saat jatuh tempo yang menyebabkan perusahaan mengalami kebangkrutan, atau menyebabkan terjadinya perjanjian khusus dengan para kreditor untuk mengurangi atau menghapus utangnya.

\section{Pengembangan Hipotesis}

Pailit adalah segala sesuatu yang berhubungan dengan peristiwa keadaan berhenti membayar utang-utang debitur yang telah jatuh tempo (Asyadhie, 2005). Penelitian terdahulu yang dilakukan Kamal (2012) tentang analisis prediksi kebangkrutan pada perusahaan perbankan go public di Bursa Efek Indonesia (dengan menggunakan Altman Z-score) dengan sampel sebanyak 20 perusahaan perbankan hasilnya menunjukkan bahwa tahun 2008, 5\% berada pada grey area dan $95 \%$ prediksi akan mengalami kebangkrutan. Tahun 2009 sebanyak 40\% berada dalam keadaan sehat, $45 \%$ mengalami kebangkrutan, dan $15 \%$ berada pada grey area. Tahun 2010 prediksi kebangkrutan pada perbankan memiliki hasil 55\% perbankan sehat, $5 \%$ berada pada grey area, dan $40 \%$ masih dalam prediksi keadaan bangkrut. Berdasarkan hal tersebut maka dirumuskan hipotesis sebagai berikut:

Hipotesis (H1): Terdapat perbedaan pada prediksi kepailitan Bank Umum Swasta Nasional Devisa yang terdaftar di Bursa Efek Indonesia antara tahun 2010, 2011, 2012, dan 2013.

\section{METODA PENELITIAN}

\section{Populasi Dan Sampel}

Populasi dalam penelitian ini adalah bank umum swasta nasional devisa yang terdaftar di BEI selama perioda penelitian yaitu antara tahun 2010 sampai 2013. Sampel dalam penelitian 21 perusahaan perbankan selama 4 tahun. Pengambilan sampel dilakukan dengan metoda purposive sampling. Adapun kriteria pemilihan sampel sebagai berikut:

a. Bank umum swasta nasional devisa yang terdaftar di BEI.

b. Bank yang memiliki kelengkapan data. 
c. Bank yang menggunakan mata uang rupiah dalam laporan keuangannya.

d. Bank yang memiliki laporan keuangan yang telah diaudit pada 2010-2013.

Data yang digunakan dalam penelitian ini diperoleh dari www.idx.co.id yang dikeluarkan bank umum swasta nasional devisa yang terdaftar di BEI perioda tahun 2010-2013.

\section{Definisi Operasional Variabel}

Berkaitan dengan analisis Z-Score, Altman Modifikasi menyatakan bahwa ada empat rasio yang dapat dikombinasikan untuk memprediksi kepailitan. Rasio- rasio tersebut adalah sebagai berikut (Bowo: 2013):

1. Modal kerja terhadap total aset (X1) adalah rasio yang digunakan untuk mengukur likuiditas aktiva perusahaan relatif terhadap total kapitalisasinya atau untuk mengukur kemampuan perusahaan dalam memenuhi kewajiban jangka pendek. Indikator yang dapat digunakan untuk mendeteksi adanya masalah pada tingkat likuiditas perusahaan adalah indikator-indikator internal seperti ketidakcukupan kas, utang dagang membengkak, dan beberapa indikator lainnya.

2. Laba ditahan terhadap total aset (X2) adalah rasio yang digunakan untuk mengukur profitabilitas kumulatif. Rasio ini mengukur akumulasi laba selama perusahaan beroperasi. Umur perusahaan berpengaruh terhadap rasio tersebut karena semakin lama perusahaan beroperasi memungkinkan untuk memperlancar akumulasi laba ditahan. Hal tersebut dapat menyebabkan perusahaan yang masih relatif muda pada umumnya akan menunjukkan hasil rasio yang rendah, kecuali yang labanya sangat besar pada masa awal berdirinya.

3. Pendapatan sebelum pajak dan bunga terhadap total aset (X3) adalah rasio yang digunakan untuk mengukur produktivitas yang sebenarnyan dari aktiva perusahaan. Rasio tersebut mengukur kemampuan perusahaan dalam menghasilkan laba dari aktiva yang digunakan. Rasio ini merupakan kontributor terbesar dari model tersebut. Beberapa indikator yang dapat kita gunakan dalam mendeteksi adanya masalah pada kemampuan profitabilitas perusahaan diantaranya adalah piutang dagang meningkat, rugi terus-menerus dalam beberapa kwartal, persediaan meningkat, penjualan menurun, dan terlambatnya hasil 
penagihan piutang.

4. Nilai pasar ekuitas terhadap nilai buku dari utang (X4) adalah rasio yang digunakan untuk mengukur seberapa banyak aktiva perusahaan dapat turun nilainya sebelum jumlah utang lebih besar daripada aktivanya dan perusahaan menjadi pailit. Modal yang dimaksud adalah gabungan nilai pasar dari modal biasa dan saham preferen, sedangkan utang mencakup utang lancar dan utang jangka panjang.

\section{Teknis Analisis Data}

Statistik deskriptif adalah statistik yang digunakan untuk menganalisa data dengan cara mendeskripsikan atau menggambarkan data yang telah terkumpul sebagaimana adanya tanpa bermaksud membuat simpulan yang berlaku untuk umum atau generalisasi (Sugiyono, 2007:206). Penelitian ini alat analisis yang digunakan adalah

\section{Analisis Metoda Altman Z-Score}

Altman Modifikasi yang digunakan untuk menganalisis potensi kepailitan perusahaan perbankan. Z-score Altman ditentukan dengan menggunakan rumus sebagai berikut (Bowo: 2013):

$$
\mathrm{Zi}=6,56 \times 1 \mathrm{i}+3,26 \times 2 \mathrm{i}+6,72 \times 3 \mathrm{i}+1,05 \times 4 \mathrm{i}
$$

Nilai $\mathrm{Z}$ adalah indeks keseluruhan fungsi multiple discriminant analysis. Menurut Altman, terdapat angka-angka cut off nilai $\mathrm{Z}$ yang dapat menjelaskan apakah perusahaan akan mengalami kegagalan atau tidak pada masa mendatang dan membaginya menjadi tiga kategori dengan kriteria penilaian sebagai berikut:

\begin{tabular}{|l|c|}
\hline & Dengan nilai \\
\hline Tidak Pailit jika Zi $>$ & 2,6 \\
Grey Area & $1,1-2,6$ \\
Pailit jika Zi $<$ & 1,1 \\
\hline
\end{tabular}

\section{Uji Normalitas Data}

Menurut Kurniawati (2012) bahwa pengujian normalitas adalah alat analisis untuk mengetahui apakah suatu data berasal dari populasi yang sama. Jika 
berdistribusi normal maka statistik yang digunakan adalah statistik parametrik dan jika data berdistribusi tidak normal maka data akan diolah menggunakan statistik nonparametrik. Pengujian normalitas pada penelitian ini menggunakan uji Kolmogorov Smirnov. Nilai Asymp. Sig. (2 tailed) $<0,05$ (alpha) maka data berdistribusi tidak normal (tidak simetris). Jika nilai Asymp. Sig. (2 tailed) $>0,05$ (alpha) maka data berdistribusi normal.

\section{Uji Beda}

Uji beda adalah alat uji yang digunakan untuk menguji keadan (sesuatu) yang terdapat dalam suatu kelompok dengan kelompok lain. Uji beda yang digunakan dalam penelitian ini adalah uji beda tiga sampel atau lebih dengan menggunakan One Way Anova. Nilai Asymp. Sig. (2 tailed) > 0,05 (alpha) maka penelitian ini menerima Ho artinya tidak ada perbedaan dan jika nilai Asymp. Sig. (2 tailed) $<0,05$ (alpha) maka penelitian ini menolak Ho artinya ada perbedaan.

\section{HASIL DAN PEMBAHASAN}

\section{Deskriptif Sampel}

\section{Tabel 1}

Daftar Nama Bank Umum Swasta Nasional Devisa

\begin{tabular}{|c|c|c|c|c|c|}
\hline No & Kode & Nama Bank & No & Kode & Nama Bank \\
\hline 1 & INPC & $\begin{array}{l}\text { Bank Artha Graha } \\
\text { Internasional Tbk. }\end{array}$ & 11 & BKSW & Bank Kesawan Tbk. \\
\hline 2 & BBKP & Bank Bukopin Tbk. & 12 & MAYA & $\begin{array}{l}\text { Bank Mayapada Internasional } \\
\text { Tbk. }\end{array}$ \\
\hline 3 & BNBA & Bank Bumi Artha Tbk. & 13 & MEGA & Bank Mega Tbk. \\
\hline 4 & BBCA & Bank Central Asia Tbk. & 14 & BCIC & Bank Mutiara Tbk. \\
\hline 5 & BNGA & Bank CIMB Niaga Tbk. & 15 & BBNP & $\begin{array}{l}\text { Bank Nusantara Parahyangan } \\
\text { Tbk. }\end{array}$ \\
\hline 6 & BDMN & $\begin{array}{l}\text { Bank Danamon Indonesia } \\
\text { Tbk. }\end{array}$ & 16 & NISP & Bank OCBC NISP Tbk. \\
\hline 7 & BAEK & Bank Ekonomi Raharja Tbk. & 17 & PNBN & Bank Pan Indonesia Tbk. \\
\hline 8 & SDRA & $\begin{array}{l}\text { Bank Himpunan Saudara } \\
1906 \text { Tbk. }\end{array}$ & 18 & BNLI & Bank Permata Tbk. \\
\hline 9 & BABP & $\begin{array}{l}\text { Bank ICB Bumiputera } \\
\text { Indonesia Tbk. }\end{array}$ & 19 & AGRO & $\begin{array}{l}\text { Bank Rakyat Indonesia } \\
\text { Agroniaga Tbk. }\end{array}$ \\
\hline 10 & BNII & $\begin{array}{l}\text { Bank Internasional Indonesia } \\
\text { Tbk. }\end{array}$ & 20 & BSIM & Bank Sinarmas Tbk. \\
\hline & & & 21 & BSWD & Bank Swadesi Tbk. \\
\hline
\end{tabular}

Sumber: www.idx.co.id (2014) 


\section{Hasil Analisis}

Berdasar hasil perhitungan Z-score pada tabel perhitungan Z-score bank umum swasta nasional devisa tahun 2010 (lampiran), terdapat 6 bank atau 29\% bank yang berada dalam kondisi pailit menurut Altman Z-score ditandai dengan nilai hasilnya yang berada di bawah 1,1 dan ada 15 bank atau $71 \%$ bank yang berapa di grey area dengan ditandai nilai di di atas 2,6 yaitu suatu area dalam perhitungan Z-score dimana perusahaan memiliki risiko kesulitan keuangan yang dapat menjurus pada kepailitan jika tidak dilakukan perbaikan kinerja perusahaan. Nilai Z-Score terendah -1,003 ada Bank Mutiara Tbk dan nilai tertinggi 2,25 pada Bank Danamon Indonesia Tbk.

Berdasar hasil perhitungan Z-score pada tabel perhitungan Z-score bank umum swasta nasional devisa tahun 2011, ada 6 bank atau 28\% bank yang berada dalam kondisi pailit menurut Altman Z-score ditandai dengan nilai hasilnya yang berada di bawah 1,1. Ada 14 bank atau $67 \%$ bank yang berapa di grey area dengan ditandai nilai di atas 2,6 yaitu suatu area dalam perhitungan Z-score dan ada 1 bank atau 5\% yang berada pada posisi bank tidak pailit ditandai dengan nilai Z-Score di atas 2,6 yaitu Bank Danamon Indonesia Tbk., hal ini menunjukkan adanya peningkatan kinerja pada Bank Danamon Indonesia Tbk. Peningkatan kinerja juga dialami beberapa bank yaitu Bank Bukopin Tbk. dan Bank Nusantara Parahyangan Tbk. yang semula berada pada posisi bank pailit menjadi pada posisi Grey area. Itu artinya suatu persahaan sudah melakukan tindakan preventif agar terhindar dari keadaan pailit. Namun, ada beberapa bank yang tidak bisa mempertahankan posisinya atau mengalami penurunan sehingga menjadi berada posisi pailit yaitu Bank ICB Bumiputera Indonesia Tbk., Bank Mega Tbk., dan Bank Permata Tbk.

Berdasar hasil perhitungan Z-score pada tabel perhitungan Z-score bank umum swasta nasional devisa tahun 2012, ada 6 bank atau 28\% bank yang berada dalam kondisi pailit menurut Altman Z-score ditandai dengan nilai hasilnya yang berada di bawah 1,1. Ada 14 bank atau $67 \%$ bank yang berapa di grey area dengan ditandai nilai di antara 1,1, sampai 2,6 yaitu suatu area dalam perhitungan Z-score dan ada 1 bank atau 5\% yang berada pada posisi bank tidak pailit yaitu Bank Danamon Tbk., bank ini mampu mempertahankan posisinya berada pada posisi tidak pailit. Bank 
Mega Tbk., Bank Permata Tbk., dan Bank Sinarmas, Tbk mampu meningkatkan kinerjanya sehingga menjadi berada pada posisi grey area yang semula berada pada posisi pailit. Di sisi lain ada beberapa bank yang mengalami penurunan dari posisi grey area menjadi pailit, yaitu Bank Mayapada Internasional Tbk., Bank Nusantara Parahyangan Tbk., dan Bank Rakyat Indonesia Agroniaga Tbk.

Berdasar hasil perhitungan Z-score pada tabel perhitungan Z-score bank umum swasta nasional devisa tahun 2013 ada 6 bank atau 29\% bank yang berada dalam kondisi pailit menurut Altman Z-score ditandai dengan nilai hasilnya yang berada di bawah 1,1. Ada 15 bank atau $71 \%$ bank yang berapa di grey area dengan ditandai nilai di antara 1,1, sampai 2,6 yaitu suatu area dalam perhitungan Z-score. Bank Danamon Tbk tidak mampu mempertahankan kinerjanya, sehingga pada tahun 2013 menjadi berada pada posisi grey area. Selain itu, Bank Internasional Indonesia Tbk. Bank Sinarmas Tbk. tidak mampu mempertahankan posisi, itu artinya tidak bisa meningkatkan kinerjanya. Namun, ada beberapa bank yang mampu meningkatkan kinerjanya yaitu, Bank ICB Bumiputera Indonesia Tbk., Bank Nusantara Parahyangan Tbk., dan Bank Mayapada Internasional Tbk.

\section{Statistik Deskriptif}

Tabel 6 (lampiran) menunjukkan bahwa nilai Z-score dengan sampel 21 bank selama tahun 2010 mempunyai nilai rata-rata 1,21595, standar deviasi 0,624570, nilai minimum -1,003, dan nilai maksimum 2,250. nilai Z-score dengan sampel 21 bank selama tahun 2011 mempunyai nilai rata-rata 1,03981, standar deviasi 1,421933, nilai minimum -4,311, dan nilai maksimum 2,770. nilai Z-score dengan sampel 21 bank selama tahun 2012 mempunyai nilai rata-rata 1,30033, standar deviasi 0,7008613 , nilai minimum -0,645, dan nilai maksimum 2.837. nilai Z-score dengan sampel 21 bank selama tahun 2013 mempunyai nilai rata-rata 1,21548, standar deviasi 0,623597, nilai minimum -0,954, dan nilai maksimum 1,994. 


\section{Uji Normalitas Data}

Tabel 2

Hasil uji Normalitas

One-Sample Kolmogorov-Smirnov Test

\begin{tabular}{|c|c|c|c|c|c|}
\hline & $\begin{array}{c}\text { Z-Score th } \\
2010\end{array}$ & $\begin{array}{r}\text { Z-Score } \\
\text { th } 2011\end{array}$ & $\begin{array}{l}\text { Z-Score } \\
\text { Th } 2012\end{array}$ & 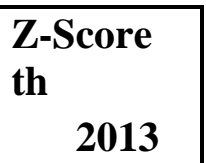 \\
\hline \multicolumn{2}{|l|}{$\mathrm{N}$} & 21 & 21 & 21 & 21 \\
\hline Normal & Mean & 1.21595 & 1.03981 & 1.30033 & $1.2154 \delta$ \\
\hline \multicolumn{2}{|c|}{ Parametersa Std. } & .624570 & 1.421933 & .700861 & .623597 \\
\hline & Deviation & & & & \\
\hline Most & Absolute & .192 & .290 & .113 & .180 \\
\hline Extreme & Positive & .183 & .166 & .093 & .107 \\
\hline \multicolumn{2}{|c|}{ Differences Negative } & -.192 & -.290 & -.113 & -.180 \\
\hline \multicolumn{2}{|c|}{ Kolmogorov-Smirnov Z } & .880 & 1.331 & .517 & .825 \\
\hline \multicolumn{2}{|c|}{ Asymp. Sig. (2-tailed) } & .421 & .058 & .952 & .503 \\
\hline
\end{tabular}

Sumber: Data sekunder,diolah (2014)

Tabel 2 menunjukkan bahwa nilai asymp sig. (2-tailed) $>$ dari 0,05 maka data berdistribusi normal. Pada tahun 2010 asymp. Sig. (2-tailed) adalah 0,421 > 0,05, tahun 2011 asymp sig. (2-tailed) adalah 0,058 > 0,05, tahun 2012 asyms sig. (2tailed) adalah 0,952 > 0,0 5, dan tahun 2012 asymp sig. (2- tailed) adalah 0,503 > 0,05 .

\section{Uji Beda}

Tabel 3

Test of Homogeneity of Variances

\begin{tabular}{|l|l|l|l|}
\hline Levene Statistic & df1 & df2 & Sig \\
\hline 1,552 & 3 & 80 & .208 \\
\hline
\end{tabular}

Sumber: Data sekunder,diolah (2014)

Tabel 3 menunjukkannilai levene test dengan Sig. 0,208 lebih besar dari taraf signifikansi $0,05(0,208>0,05)$. Berdasarkan hal ini menunjukkan bahwa keempat 
varians sampel adalah sama dengan tingkat kepercayaan $95 \%$.

\section{Tabel 4}

ANOVA

\begin{tabular}{|l|r|r|r|r|r|}
\hline \multicolumn{1}{|c|}{ Z-Sore } & \multicolumn{1}{|c|}{$\begin{array}{c}\text { Sum of } \\
\text { Squares }\end{array}$} & \multicolumn{1}{c|}{ Df } & Mean Square & \multicolumn{1}{c|}{$\boldsymbol{F}$} & \multicolumn{1}{c|}{ Sig. } \\
\hline Between Groups & .756 & 3 & .252 & .306 & .821 \\
Within Groups & 65.841 & 80 & .823 & & \\
Total & 66.598 & 83 & & & \\
\hline
\end{tabular}

Sumber: Data sekunder,diolah (2014)

Tabel 4 menunjukkan hasil uji ANOVA dengan sig sebesar 0,821 lebih besar dari $0,05(0,821>0,05)$, maka Ho diterima sehinggga simpulan dari penelitian ini adalah tidak ada perbedaan Z-score antara tahun 2010, 2011, 2012, dan 2013.

\section{SIMPULAN, KETERBATASAN, DAN SARAN}

Penelitian ini merupakan penelitian emperis yang bertujuan untuk mengetahui keadaan bank. Apakah berada pada posisi pailit, grey area, dan tidak pailit. Bank tersebut adalah bank umum swasta nasional devisa yang terdaftar di Bursa Efek Indonesia. Dengan penelitian ini diharapkan perbankan dapat melakukan tindakan preventif sebelum terjadi kepailitan. Simpulan penelitian ini adalah sebagai berikut:

1. Pada tahun 2010 bank umum swasta nasional devisa yang terdaftar di Bursa Efek Indonesia terdapat 6 bank atau 29\% bank yang berada dalam kondisi pailit, 15 bank atau $71 \%$ bank yang berapa di grey area, dan dan tidak ada bank yang berada pada prediksi tidak pailit.

2. Pada tahun 2011 bank umum swasta nasional devisa yang terdaftar di Bursa Efek Indonesia 29\% bank yang berada dalam kondisi pailit, 67\% bank yang berapa di grey area dan 5\% yang berada pada prediksi bank tidak pailit.

3. Pada tahun 2012 bank umum swasta nasional devisa yang terdaftar di Bursa Efek Indonesia 29\% bank yang berada dalam kondisi pailit, 67\% bank yang berapa di grey area, dan 5\% bank yang berada pada prediksi bank tidak pailit.

4. Pada tahun 2013 bank umum swasta nasional devisa yang terdaftar di Bursa Efek Indonesia $29 \%$ bank yang berada dalam prediksi pailit, $71 \%$ bank yang 
berapa di grey area, dan tidak ada bank yang berada pada prediksi tidak pailit.

5. Hasil uji ANOVA dengan Sig sebesar 0,821 lebih besar dari 0,05 (0,821>0,05), maka Ho diterima sehinggga simpulan dari penelitian ini adalah tidak ada perbedaan Z-score pada prediksi kepailitan bank umum swasta nasional devisa yang terdaftar di Bursa Efek Indonesia antara tahun 2010, 2011, 2012, dan 2013. Varians sampel dalam penelitian ini juga sama yaitu ditunjukkan dengan dengan $0,208>0,05$.

Keterbatasan dalam penelitian ini yaitu metoda yang digunakan dalam penelitian ini adalah metoda Altman Z-Score, tidak membandingkan dengan metoda lain. Selain itu, perusahaan yang digunakan sebagai objek penelitian hanya bank umum swasta nasional devisa yang terdaftar di BEI, tidak dengan sampel bank yang terindikasi pailit agar hasilnya lebih akurat.

Berdasar keterbatasan yang ada, maka saran yang dapat diajukan dalam penelitian ini adalah seharusnya metoda yang digunakan dalam penelitian ini adalah metoda CAMEL sesuai yang telah ditentukan oleh Bank Indonesia. Untuk penelitian selanjutnya sebaiknya objek penelitian ditambahkan sampel bank yang terindikasi pailit agar hasilnya lebih akurat. Selain itu, penilaian kinerja keuangan dengan menggunakan Altman Z-Score tidak dapat menunjukkan hasil yang sebenarnya, namun tidak ada salahnya bagi manajemen perusahaan tetap dapat melakukan evaluasi dan pengawasan dalam meningkatkan kinerja perusahaan agar terhindar dari potensi kepailitan.

\section{DAFTAR PUSTAKA}

Altman, E. I. 1968. Financial Ratios, Discriminant Analysis and The Prediction of Corporate Bankruptcy. The Journal of FINANCE. Didapatkan: <http://onlinelibrary.wiley.com/doi/10.1111/j.15406261.1968.tb00843.x/ful[06> Juni 2014].

Ary, Monica Rahardian. 2004. Studi Potensi Kebangkrutan Perusahaan Publik di Indonesia. Tesis. Semarang: Universitas Diponegoro.

Asakdiyah, Salamatun. 2006. Manajemen Keuangan 1. Yogyakarta. 
Asyhadie, Zaeni. 2005. Hukum Bisnis. Mataram: Rajawali Pers.

Bank Gagal. 2014. Didapatkan: <http://kinerjabank.com [19> Oktober 2014].

Bowo, Ari, Unggul Nusantoro. 2013. Analisis Perbandingan Model Altman Modifikasi dan Springate untuk Memprediksi Kebangkrutan pada Perusahaan Perbankan yang Terdaftar di Bursa Efek Indonesia Sebelum dan Sesudah Adanya Lembaga Penjamin Simpanan. Jurnal Akuntansi. Vol 1 No 2. Yogyakarta: Universitas Sarjanawiyata Tamansiswa.

Departemen Pendidikan Nasional. 2011. Kamus Besar Bahasa Indonesia Pusat Bahasa. Jakarta: Gramedia Pustaka Utama.

Endri. 2009. Prediksi Kebangkrutan Bank untuk Menghadapi dan Mengelola Perubahan Lingkungan Bisnis: Analisis Model Altman's Z-Score. Didapatkan: $<$ http://perbanasinstitute.ac.id/attachments/article/623/Prediksi endri.PDF[2> Oktober 2014].

Gamayuni, Rindu Rika. 2011. Analisis Ketepatan Model Altman Sebagai Alat untuk Memprediksi Kebangkrutan (Studi Empiris pada Perusahaan Manufaktur di Bei). Jurnal Akuntansi dan Keuangan Volume 16 Nomor 2.

Hadi, Syamsul. 2008. Pemilihan Prediktor Delisting Terbaik (Perbandingan Antara the Zmijewski Model, The Altman Model, dan The Springate Model). Simposium Nasional Akuntansi (Sna) Ke Xi. Pontianak.

Harahap, Sofyan Safri. 1997. Analisis Kritis Atas Laporan Keuangan. Jakarta: PT.Raja Grafindo Persada.

http://www.idx.co.id. [15 September 2015].

Ikatan Akuntan Indonesia. 2012. Standar Akuntansi Keuangan. PSAK. Cetakan Keempat, Buku Satu. Jakarta: Salemba Empat.

Ismail. 2010. Manajemen Perbankan. Surabaya: Kencana Prenada Media Group.

Kamal, S. M. 2012. Analisis Prediksi Kebangkrutan pada Perusahaan Perbankan Go Public di Bursa Efek Indonesia. Universitas Hasanuddin Makassar. Didapatkan <http://222.124.222.229/handle/123456789/1051 [10> juni 2014].

Kasmir. 2008. Manajemen perbankan . Jakarta: PT Raja Grafindo Persada. 
Kurniawati, Indah. 2012. Praktikum pengolahan data elektronik (PDE). Yogyakarta: Universitas Ahmad Dahlan.

Munawir, S. 2002. Analisis Informasi Keuangan. Yogyakarta: Liberty Yogyakarta.

Rivai, Veithzal, Andria, Idroes permata, Ferry N. 2007. Bank and Financial Institution Management: Conventional \& Sharia System. Jakarta. PT Raja Grafindo Persada.

Sartono. 2012. Indonesia HR Forum: Pailit Vs Bangkrut, [online]: < https://www.linkedin.com/groups/Pailit [15>September2014).

Setyorini. 1999. Sna II dan Rapat Anggota. Malang: IAI Kapd.

Sugiyono. 2007. Metoda Penelitian Bisnis. Alfabeta: Bandung.

Taswan. 2006. Manajemen Perbankan. Yogyakarta: UPP STIM YKPN 


\section{LAMPIRAN}

Tabel

Perhitungan Z-Score

Bank Umum Swasta Nasional Devisa Tahun 2010

\begin{tabular}{|c|c|c|c|c|c|c|c|}
\hline No. & Kode & $\mathbf{X}_{1}$ & $\mathbf{X}_{2}$ & $\mathbf{X}_{3}$ & $X_{4}$ & Z-Score & $\begin{array}{c}\text { Hasil } \\
\text { Analisis } \\
\end{array}$ \\
\hline 1 & INPC & 0,768 & $(0,062)$ & 0,410 & 0,00118 & 1,117 & Grey Area \\
\hline 2 & BBKP & 0,282 & 0,114 & 0,383 & 0,10371 & 0,883 & Pailit \\
\hline 3 & BNBA & 0,899 & 0,245 & 0,376 & 0,06398 & 1,584 & Grey Area \\
\hline 4 & BBCA & 0,787 & 0,287 & 0,383 & 0,09916 & 1,556 & Grey Area \\
\hline 5 & BNGA & 0,958 & 0,137 & 0,396 & 0,08123 & 1,572 & Grey Area \\
\hline 6 & BDMN & 1,260 & 0,277 & 0,605 & 0,10816 & 2,250 & Grey Area \\
\hline 7 & BAEK & 0,794 & 0,267 & 0,316 & 0,00001 & 1,377 & Grey Area \\
\hline 8 & SDRA & 0,649 & 0,156 & 0,544 & 0,00069 & 1,351 & Grey Area \\
\hline 9 & BABP & 0,925 & 0,020 & 0,349 & 0,00002 & 1,294 & Grey Area \\
\hline 10 & BNII & 0,335 & 0,095 & 0,329 & 0,01592 & 0,774 & Pailit \\
\hline 11 & BKSW & 0,380 & 0,016 & 0,612 & 0,05070 & 1,059 & Pailit \\
\hline 12 & MAYA & 0,833 & 0,068 & 0,450 & 0,03225 & 1,384 & Grey Area \\
\hline 13 & MEGA & 0,872 & 0,170 & 0,383 & 0,00007 & 1,425 & Grey Area \\
\hline 14 & $\mathrm{BCIC}$ & 1,050 & $(2,543)$ & 0,491 & 0,00000 & $(1,003)$ & Pailit \\
\hline 15 & BBNP & 0,577 & 0,156 & 0,343 & 0,00000 & 1,076 & Pailit \\
\hline 16 & NISP & 0,853 & 0,189 & 0,296 & 0,00371 & 1,341 & Grey Area \\
\hline 17 & PNBN & 1,299 & 0,199 & 0,363 & 0,01791 & 1,879 & Grey Area \\
\hline 18 & BNLI & 1,004 & $(0,052)$ & 0,370 & 0,01347 & 1,335 & Grey Area \\
\hline 19 & AGRO & 0,649 & $(0,088)$ & 0,470 & 0,19312 & 1,225 & Grey Area \\
\hline 20 & BSIM & 0,413 & 0,042 & 0,383 & 0,01863 & 0,857 & Pailit \\
\hline 21 & BSWD & 1,286 & 0,235 & 0,558 & 0,00000 & 2,078 & Grey Area \\
\hline
\end{tabular}


Tabel

Perhitungan Z-Score

Bank umum Swasta Nasional Devisa Tahun 2011

\begin{tabular}{|r|c|r|r|r|r|r|l|}
\hline No. & Kode & $\mathbf{X} 1$ & $\mathbf{X}_{\mathbf{2}}$ & $\mathbf{X 3}$ & $\mathbf{X} \mathbf{4}$ & Z-Score & $\begin{array}{c}\text { Hasil } \\
\text { Analisis }\end{array}$ \\
\hline 1 & INPC & 0,912 & $(0,036)$ & 0,383 & 0,00408 & 1,263 & Grey Area \\
\hline 2 & BBKP & 0,617 & 0,127 & 0,403 & 0,09467 & 1,242 & Grey Area \\
\hline 3 & BNBA & 0,866 & 0,258 & 0,396 & 0,00381 & 1,524 & Grey Area \\
\hline 4 & BBCA & 0,781 & 0,313 & 0,376 & 0,09080 & 1,561 & Grey Area \\
\hline 5 & BNGA & 1,030 & 0,176 & 0,450 & 0,00705 & 1,663 & Grey Area \\
\hline 6 & BDMN & 1,870 & 0,284 & 0,538 & 0,07891 & 2,770 & Tidak Pailit \\
\hline 7 & BAEK & 0,781 & 0,287 & 0,215 & 0,00008 & 1,283 & Grey Area \\
\hline 8 & SDRA & 0,820 & 0,117 & 0,511 & 0,11923 & 1,567 & Grey Area \\
\hline 9 & BABP & 0,138 & $(0,026)$ & 0,309 & 0,00001 & 0,421 & Pailit \\
\hline 10 & BNII & 0,728 & 0,098 & 0,349 & 0,00288 & 1,178 & Grey Area \\
\hline 11 & BKSW & 0,354 & 0,016 & 0,276 & 0,15512 & 0,801 & Pailit \\
\hline 12 & MAYA & 0,564 & 0,098 & 0,491 & 0,00008 & 1,153 & Grey Area \\
\hline 13 & MEGA & 0,446 & 0,088 & 0,396 & 0,00005 & 0,931 & Pailit \\
\hline 14 & BCIC & 0,656 & $(2,024)$ & 0,551 & 0,00000 & $(0,817)$ & Pailit \\
\hline 15 & BBNP & 0,538 & 0,156 & 0,417 & 0,00021 & 1,111 & Grey Area \\
\hline 16 & NISP & 0,984 & 0,179 & 0,329 & 0,02814 & 1,521 & Grey Area \\
\hline 17 & PNBN & 1,299 & 0,222 & 0,417 & 0,00957 & 1,947 & Grey Area \\
\hline 18 & BNLI & $(4,684)$ & $(0,000)$ & 0,370 & 0,00403 & $(4,311)$ & Pailit \\
\hline 19 & AGRO & 1,830 & $(0,046)$ & 0,457 & 0,14529 & 2,387 & Grey Area \\
\hline 20 & BSIM & 0,361 & 0,052 & 0,383 & 0,01140 & 0,807 & Pailit \\
\hline 21 & BSWD & 1,141 & 0,222 & 0,470 & 0,00000 & 1,834 & Grey Area \\
\hline Sur & Ber & & & & & \\
\hline
\end{tabular}

Sumber: data diolah 
Tabel

Perhitungan Z-Score

Bank Umum Swasta Nasional Devisa Tahun 2012

\begin{tabular}{|c|c|r|r|c|c|r|l|}
\hline No. & Kode & $\mathbf{X 1}$ & $\mathbf{X 2}$ & $\mathbf{X 3}$ & $\mathbf{X} 4$ & Z-Score & $\begin{array}{c}\text { Hasil } \\
\text { Analisis }\end{array}$ \\
\hline 1 & INPC & 0,735 & 0,010 & 0,356 & 0,01848 & 1,119 & Grey Area \\
\hline 2 & BBKP & 0,577 & 0,143 & 0,383 & 0,04207 & 1,146 & Grey Area \\
\hline 3 & BNBA & 0,813 & 0,264 & 1,048 & 0,01006 & 2,136 & Grey Area \\
\hline 4 & BBCA & 0,846 & 0,336 & 0,336 & 0,09231 & 1,610 & Grey Area \\
\hline 5 & BNGA & 1,141 & 0,218 & 0,417 & 0,00104 & 1,778 & Grey Area \\
\hline 6 & BDMN & 1,922 & 0,319 & 0,524 & 0,07172 & 2,837 & Tidak Pailit \\
\hline 7 & BAEK & 0,768 & 0,277 & 0,262 & 0,00003 & 1,307 & Grey Area \\
\hline 8 & SDRA & 0,912 & 0,111 & 0,470 & 0,27035 & 1,763 & Grey Area \\
\hline 9 & BABP & 0,341 & $(0,033)$ & 0,302 & 0,07742 & 0,688 & Pailit \\
\hline 10 & BNII & 0,748 & 0,111 & 0,343 & 0,00066 & 1,202 & Grey Area \\
\hline 11 & BKSW & 0,636 & $(0,007)$ & 0,188 & 0,02184 & 0,840 & Pailit \\
\hline 12 & MAYA & 0,295 & 0,108 & 0,457 & 0,02936 & 0,889 & Pailit \\
\hline 13 & MEGA & 0,604 & 0,153 & 0,390 & 0,00024 & 1,147 & Grey Area \\
\hline 14 & BCIC & 0,623 & $(1,712)$ & 0,444 & 0,00000 & $(0,645)$ & Pailit \\
\hline 15 & BBNP & 0,499 & 0,156 & 0,376 & 0,00000 & 1,031 & Pailit \\
\hline 16 & NISP & 1,063 & 0,173 & 0,302 & 0,00099 & 1,539 & Grey Area \\
\hline 17 & PNBN & 1,371 & 0,231 & 0,410 & 0,00920 & 2,022 & Grey Area \\
\hline 18 & BNLI & 1,082 & 0,033 & 0,323 & 0,00275 & 1,440 & Grey Area \\
\hline 19 & AGRO & 0,190 & $(0,013)$ & 0,309 & 0,00589 & 0,492 & Pailit \\
\hline 20 & BSIM & 0,630 & 0,104 & 0,423 & 0,00464 & 1,162 & Grey Area \\
\hline 21 & BSWD & 1,109 & 0,218 & 0,477 & 0,00015 & 1,804 & Grey Area \\
\hline
\end{tabular}


Tabel

Perhitungan Z-Score

Bank umum Swasta Nasional Devisa Tahun 2013

\begin{tabular}{|c|c|c|c|r|r|r|l|}
\hline No. & Kode & $\mathbf{X 1}$ & $\mathbf{X 2}$ & $\mathbf{X 3}$ & $\mathbf{X} \mathbf{4}$ & Z-Score & $\begin{array}{c}\text { Hasil } \\
\text { Analisis }\end{array}$ \\
\hline 1 & INPC & 0,768 & 0,046 & 0,390 & 0,00242 & 1,205 & Grey Area \\
\hline 2 & BBKP & 0,282 & 0,166 & 0,336 & 0,08000 & 0,864 & Pailit \\
\hline 3 & BNBA & 0,899 & 0,261 & 0,316 & 0,00204 & 1,477 & Grey Area \\
\hline 4 & BBCA & 0,787 & 0,375 & 0,349 & 0,09228 & 1,604 & Grey Area \\
\hline 5 & BNGA & 0,958 & 0,261 & 0,417 & 0,00098 & 1,636 & Grey Area \\
\hline 6 & BDMN & 1,260 & 0,319 & 0,242 & 0,03526 & 1,856 & Grey Area \\
\hline 7 & BAEK & 0,794 & 0,277 & 0,282 & 0,00005 & 1,353 & Grey Area \\
\hline 8 & SDRA & 0,649 & 0,140 & 0,558 & 0,09146 & 1,439 & Grey Area \\
\hline 9 & BABP & 0,925 & $(0,062)$ & 0,222 & 0,08656 & 1,171 & Grey Area \\
\hline 10 & BNII & 0,335 & 0,124 & 0,363 & 0,00042 & 0,822 & Pailit \\
\hline 11 & BKSW & 0,380 & 0,000 & 0,168 & 0,00645 & 0,555 & Pailit \\
\hline 12 & MAYA & 0,833 & 0,114 & 0,491 & 0,06602 & 1,504 & Grey Area \\
\hline 13 & MEGA & 0,872 & 0,026 & 0,282 & 0,00021 & 1,181 & Grey Area \\
\hline 14 & BCIC & 1,050 & $(2,044)$ & 0,040 & 0,00000 & $(0,954)$ & Pailit \\
\hline 15 & BBNP & 0,577 & 0,160 & 0,417 & 0,00835 & 1,162 & Grey Area \\
\hline 16 & NISP & 0,853 & 0,179 & 0,316 & 0,00040 & 1,348 & Grey Area \\
\hline 17 & PNBN & 1,299 & 0,254 & 0,423 & 0,01776 & 1,994 & Grey Area \\
\hline 18 & BNLI & 1,004 & 0,059 & 0,370 & 0,00166 & 1,434 & Grey Area \\
\hline 19 & AGRO & 0,649 & 0,023 & 0,349 & 0,00000 & 1,022 & Pailit \\
\hline 20 & BSIM & 0,413 & 0,134 & 0,329 & 0,00428 & 0,881 & Pailit \\
\hline 21 & BSWD & 1,286 & 0,228 & 0,457 & 0,00006 & 1,971 & Grey Area \\
\hline
\end{tabular}

Tabel

Descriptive Statistics

\begin{tabular}{|l|r|r|r|r|r|}
\hline & $\mathrm{N}$ & Mean & Std. Deviation & Minimum & Maximum \\
\hline Z-Score th 2010 & 21 & 1.21595 & .624570 & -1.003 & 2.250 \\
Z-Score th 2011 & 21 & 1.03981 & 1.421933 & -4.311 & 2.770 \\
Z-Score th 2012 & 21 & 1.30033 & .700861 & -.645 & 2.837 \\
Z-Score th 2013 & 21 & 1.21548 & .623597 & -.954 & 1.994 \\
\hline
\end{tabular}

